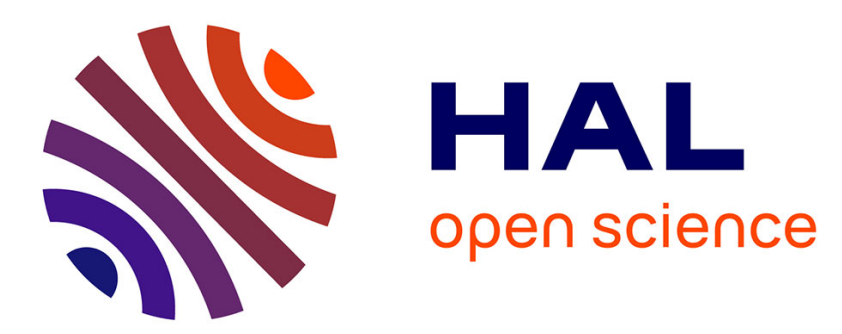

\title{
Characterization of subsurface cylindrical structures by photothermal wave techniques
}

\author{
A. Ocariz, A. Sánchez-Lavega, A. Salazar
}

\section{To cite this version:}

A. Ocariz, A. Sánchez-Lavega, A. Salazar. Characterization of subsurface cylindrical structures by photothermal wave techniques. Journal de Physique IV Proceedings, 1994, 04 (C7), pp.C7-583-C7-586. 10.1051/jp4:19947137 . jpa-00253192

\section{HAL Id: jpa-00253192 https://hal.science/jpa-00253192}

Submitted on 1 Jan 1994

HAL is a multi-disciplinary open access archive for the deposit and dissemination of scientific research documents, whether they are published or not. The documents may come from teaching and research institutions in France or abroad, or from public or private research centers.
L'archive ouverte pluridisciplinaire HAL, est destinée au dépôt et à la diffusion de documents scientifiques de niveau recherche, publiés ou non, émanant des établissements d'enseignement et de recherche français ou étrangers, des laboratoires publics ou privés. 


\title{
Characterization of subsurface cylindrical structures by photothermal wave techniques
}

\author{
A. Ocariz, A. Sánchez-Lavega and A. Salazar \\ Dpto. Fúsica Aplicada I, ETS Ingenieros Industriales y de Telecomunicación, Universidad del País Vasco, \\ Alda. Urquijo s/n, 48013 Bilbao, Spain
}

\begin{abstract}
A thermal wave theoretical and experimental study is performed on fabricated subsurface cylinders (air holes and stainless steel inclusions) immersed in opaque samples (Al alloy and epoxy respectively). These structures simulate buried defects and fiber reinforced composites with metallic and polymeric matrices. They are used to analyze the potentiality of photothermal methods to make a quantitative characterization of these materials.
\end{abstract}

\section{INTRODUCTION}

We present a theoretical and experimental work on the potentiality of the photothermal wave techniques to characterize subsurface cylindrical features on opaque samples under a variety of thermal properties for the base sample and for the cylinders. Some of the configurations analyzed are intended to simulate advanced structural materials of special interest in the aerospatial industry, such as composites with metallic and polymeric matrix reinforced by oriented fibers (the cylinders), of non- metallic (graphite) and metallic (stainless steel, Al alloy) nature. We also study the case of adiabatic holes as an example of subsurface defects.

\section{THEORETICAL MODELS}

The theoretical models are based on the single scattering of the thermal wave by the subsurface cylinders embedded within a given matrix. We have explored the scattering behavior of two types of thermal waves, plane and spherical. The resulting surface temperature (magnitude and phase) is then numerically calculated by means of two different models. One is based on the partial wave expansion of planar and spherical waves 1 , the other one employs the Green's integral theorem 1,2 . This extends a previous theoretical work on the thermal wave scattering by subsurface cylindrical defects which were performed for planar excitation using the partial wave expansion method 1 .

For a modulated (frequency $\omega$ ) exciting beam, the surface temperature $T_{S}(r)$ obeys the heat diffusion equation which for periodic energy deposition is 1,2

$$
\nabla^{2} \mathrm{~T}_{\mathrm{s}}(\mathbf{r})+\mathrm{q}^{2}(\mathbf{r}) \mathrm{T}_{\mathrm{s}}(\mathbf{r})=-\mathrm{f}(\mathbf{r})
$$

being $\mathrm{q}=(1+\mathrm{i}) / \mu$ the thermal wave vector, $\mu=(2 \mathrm{k} / \omega)^{1 / 2}$ the thermal diffusion length $(\mathrm{k}$ is the thermal diffusivity), $\mathrm{f}(\mathbf{r})=\mathrm{Q}(\mathbf{r}) / \mathrm{K}$ the source term ( $\mathrm{Q}$ is the heat deposited per unit volume in the solid). The following boundary conditions are assumed 1,2 for all the cases :

$$
\text { adiabatic sample surface }\left(\mathrm{K}_{\text {sample }} \gg \mathrm{K}_{\text {air }}\right): \nabla \mathrm{T} \mathrm{I}_{\text {sample surface }}=0
$$


whereas for the cylinder, depending on the case :
(A) adiabatic cylinder :
$\nabla \mathrm{T}_{\mathrm{c}}=0$
$r=a$
(B) non adiabatic cylinder :
$\mathrm{K}_{\mathrm{S}} \nabla \mathrm{T}_{\mathrm{s}}=\mathrm{K}_{\mathrm{c}} \nabla \mathrm{T}_{\mathrm{c}}$
$\mathrm{r}=\mathrm{a}$
( $s=$ sample, $c=$ cylinder)
$\mathrm{T}_{\mathrm{s}}=\mathrm{T}_{\mathrm{c}}$
$\mathrm{r}=\mathbf{a}$

We study the scattering for two kind of wave geometries : (1) Planar (extended excitation) ; (2) Spherical (point-like excitation). In all cases the sample is optically opaque at the pump laser wavelength.

For space reasons, we consider here only the theoretical case of an adiabatic cylinder (e.g. a hole) within a metallic conducting sample that scatters an incident plane thermal wave. The geometry is shown in figure 1. The single scattering solution to (1) with (2) and (3) is obtained by two methods :

a) Green's function solution in cylindrical coordinates :

$$
\begin{aligned}
& T_{s}(r, \varphi)=\frac{i C}{q K}\left(1-e^{i q d}\right) \iint_{\text {S(cylunder) }} e^{-i q a \sin \varphi^{\prime}}\left[\frac{\partial}{\partial r^{\prime}} G\left(r, \varphi, y ; r^{\prime}, \varphi^{\prime}, y^{\prime}\right)\right]_{r^{\prime}=a} d \varphi^{\prime} d y^{\prime} \\
& \text { where the Green's function is: } G\left(r ; r^{\prime}\right)=\frac{1}{4 \Pi}\left[\frac{e^{i q R_{1}}}{R_{1}}+\frac{e^{i q R_{2}}}{R_{2}}\right]
\end{aligned}
$$

with:

$$
\begin{gathered}
R_{1}=\left[r^{2}+r^{\prime 2}-2 r r^{\prime} \cos \left(\varphi-\varphi^{\prime}\right)+y^{\prime 2}\right]^{1 / 2} \\
R_{2}=\left[r^{2}+r^{\prime 2}-2 r r^{\prime} \cos \left(\varphi+\varphi^{\prime}\right)-4 d\left(r \sin \varphi+r^{\prime} \sin \varphi^{\prime}\right)+y^{\prime 2}\right]^{1 / 2}
\end{gathered}
$$

where for simplicity $y=0$ and $C$ is a constant that includes the exciting beam power.

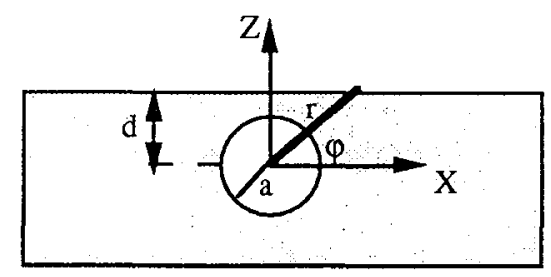

Figure 1: Geometry of the problem

b) Partial wave expansion in cylindrical waves of the incident and scattered wave:

$$
\mathrm{T}_{\mathrm{s}}(\mathrm{r}, \varphi)=\frac{\mathrm{i} \mathrm{C}}{\mathrm{K}} \mathrm{e}^{\mathrm{iqd}}\left[\mathrm{J}_{0}(\mathrm{qr})+2 \sum_{\mathrm{m}=1}^{\infty} \mathrm{i}^{\mathrm{m}} \cos (\mathrm{m} \varphi) \mathrm{J}_{\mathrm{m}}(\mathrm{qr})\right]+\sum_{\mathrm{m}=0}^{\infty} \mathrm{A}_{\mathrm{m}} \cos (\mathrm{m} \varphi) \mathrm{H}_{\mathrm{m}}(\mathrm{qr})
$$

with $\mathrm{J}_{\mathrm{m}}$ the Bessel function, $\mathrm{H}_{\mathrm{m}}$ the Hankel function and $\mathrm{A}_{\mathrm{m}}$ are obtained from the boundary conditions :

$$
A_{0}=\frac{-i C}{K} \frac{J_{1}(q a)}{H_{1}(q a)} e^{i q d} \quad ; \quad A_{m}=-2 \frac{C}{K} i^{m+1} \frac{J_{m}-1(q a)-J_{m+1}(q a)}{H_{m}-1(q a)-H_{m+1}(q a)} e^{i q d}
$$

Numerical calculations of the amplitude and phase of $T_{S}(r, \varphi)$ for the two models are shown in figure 2. There is a remarkable similar trend in the two cases although some differences are evident as the thermal diffusion length becomes larger than the depth and size of the cylinder. 
$\mu_{s} \sim$ depth of the cylinder ( $\left.d-a\right)$, corresponding to the limit case in which the thermal wave reflects back to the surface and multiple reflection is still avoided. The best agreement between both models is found when $\mu_{\mathrm{s}}<\mathrm{a}$, but they show notorious differences if $\mu_{\mathrm{s}}>2 \mathrm{a}$. The Green's function approach does not give an accurate solution for the case of a cylindrical scatterer when $\mu_{s}>2$ a.
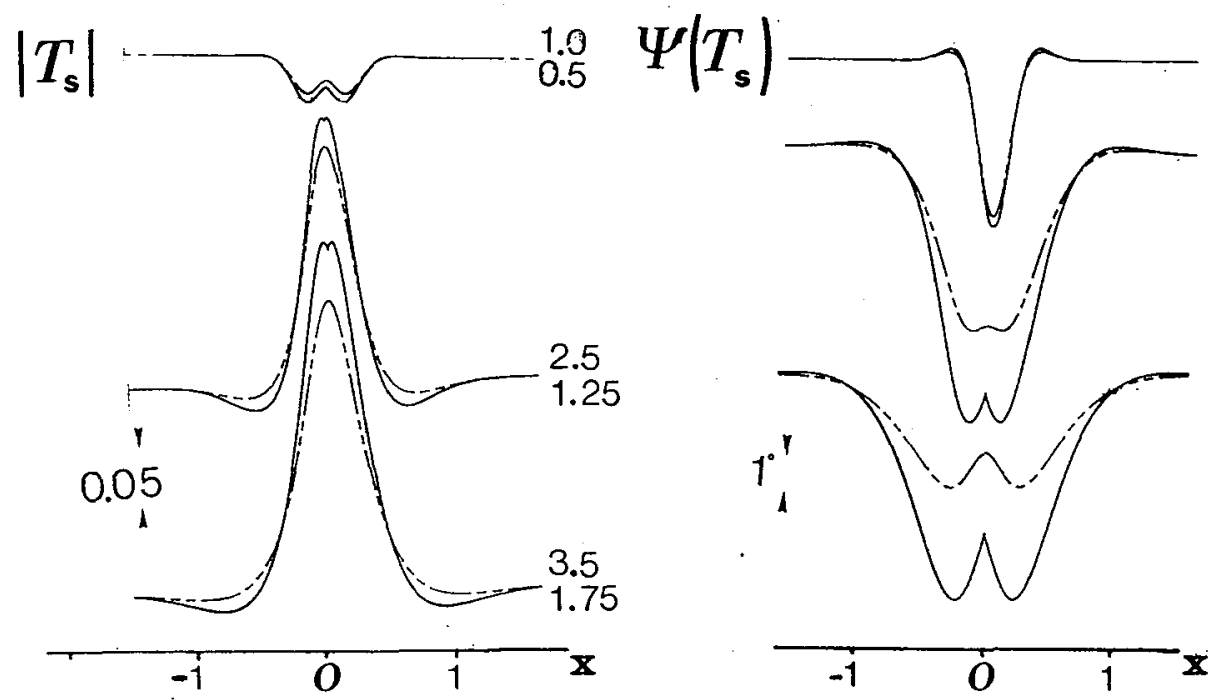

Figure 2: Theoretical calculations of the amplitude and phase of the surface temperature for the single scattering of a planar thermal wave by a buried adiabatic cylinder. Continuous line : Green's integral model; dashed line : partial wave expansion model. The numbers for each curve are the ratios $\mu_{s} / \mathrm{a}$ and $\mu_{s} /(d-a)$ for each case respectively.

\section{EXPERIMENTAL RESULTS}

Experimental measurements were performed using a mirage device on different types of constructed samples. Instead of a direct measure of the temperature, we retrieve its behaviour by measuring the normal component of the mirage deflection $\phi_{\mathrm{n}}$. The reason is double. On one hand, the mirage technique has a very high sensitivity 2 . On the other hand, $\phi_{n}$ shows a good correlation in the form and relative values of the surface temperature ${ }^{2}$.

Two type of samples were fabricated : (1) Cylindrical holes (adiabatic) within an $\mathrm{Al}$ alloy 7075,T6 $\left(\mathrm{a}=250 \mu \mathrm{m}, \mathrm{d}_{\mathrm{o}}=\mathrm{d}-\mathrm{a}=50 \mu \mathrm{m} ; \mathrm{k}_{\mathrm{Al}}=50 \mathrm{~mm}^{2} / \mathrm{s}, \mathrm{K}_{\mathrm{Al}}=120 \mathrm{~W} / \mathrm{mK} ; \mathrm{k}_{\text {air }}=20 \mathrm{~mm}^{2} / \mathrm{s}, \mathrm{K}_{\mathrm{air}}=0.026 \mathrm{~W} / \mathrm{mK}\right)$, (2) Different types of cylindrical inclusions at $\mathrm{d}_{0}=20-50 \mu \mathrm{m}$ within an opaque epoxy (with $\mathrm{k}_{\mathrm{ep}}=0.2 \mathrm{~mm}^{2} / \mathrm{s}, \mathrm{K}_{\mathrm{ep}}=0.4 \mathrm{~W} / \mathrm{mK}$ ). We have used cylindrical inclusions made of silver, pencil graphite, copper, ... but here we represent the results for an stainless steel cylinder $\left(\mathrm{k}_{\mathrm{ss}}=10 \mathrm{~mm} / \mathrm{s}\right.$, $\left.\mathrm{K}_{\mathrm{ss}}=60 \mathrm{~W} / \mathrm{mK}, \mathrm{a}=400 \mu \mathrm{m}\right)$. Note that these two samples represent extreme cases in the thermal behaviour.

Figure 3 outline our experimental measurements of the amplitude and phase of $\phi_{\mathrm{n}}$ for sample (1) and sample (2) using plane wave excitation. There is a good qualitative agreement with the theoretical predictions of section 2 and with those of Favro et al. (ref. 1). They also agree with published measurements for inclusions by means of a photoacoustic technique ${ }^{3}$.

The analysis of the profiles for different frequencies in terms of empirical models gives the size, depth and nature of the subsurface structure, and serve also to detect microstructural defects as matrix cracks, broken fibers and disbonds between fiber and matrix when employing as a probe spherical thermal waves. 

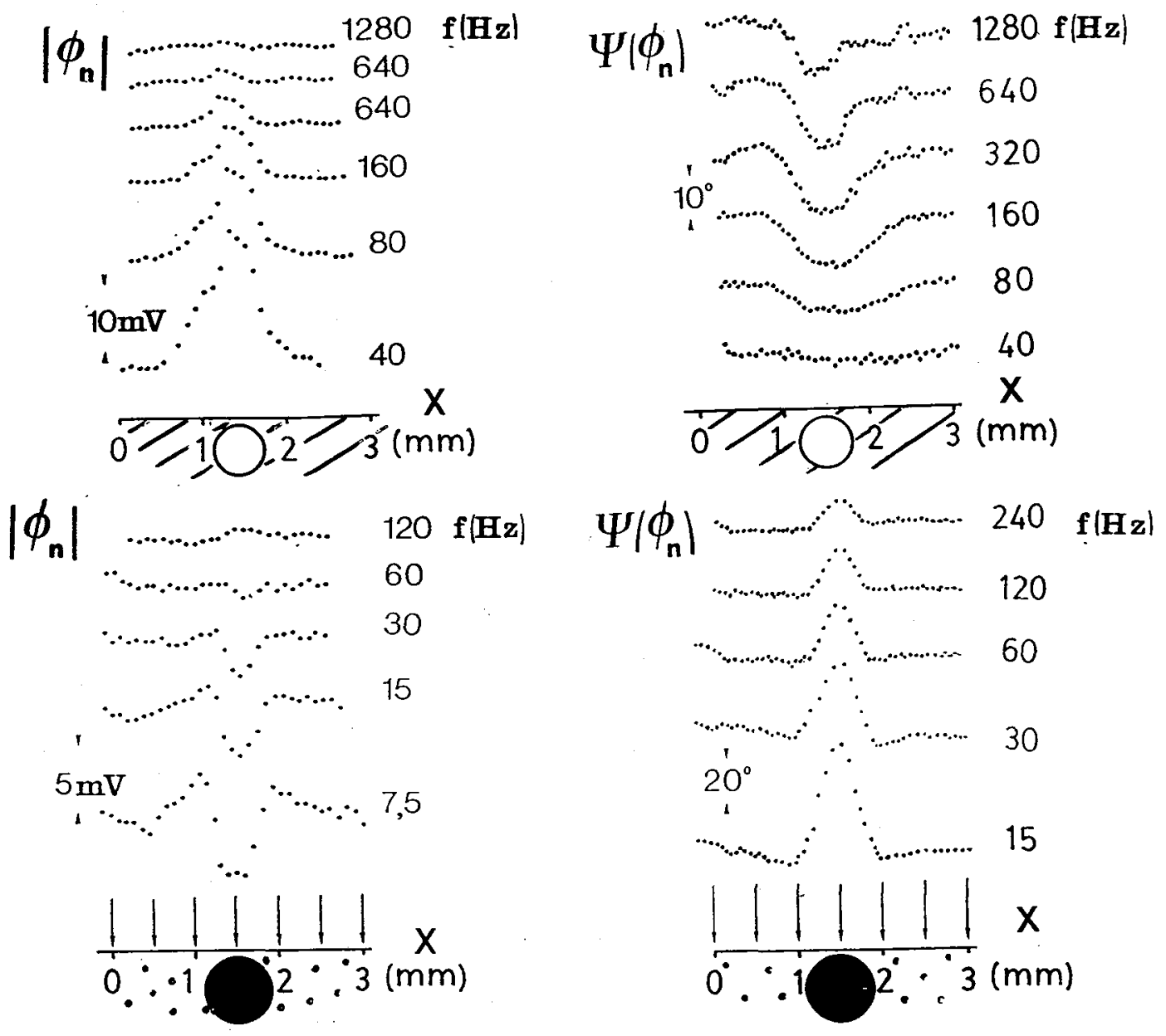

Figure 3: Experimental scans of the amplitude and phase of $\phi_{n}$ at the indicated frequencies. Upper panel: Air cylindrical hole in an Al alloy (depth $0.05 \mathrm{~mm}$, diameter $0.5 \mathrm{~mm}$ ); Lower panel : Stainless steel inclusion within an epoxy matrix (depth $\sim 0.02 \mathrm{~mm}$, diameter $0.8 \mathrm{~mm}$ ).

\section{ACKNOWLEDGEMENTS}

This work was supported by the Universidad del País Vasco research grant E173/92.

\section{REFERENCES}

[1] Favro L.D., Kuo P.K.and Thomas R.L., in "Photoacoustic and Thermal Wave Phenomena in Semiconductors" edited by A. Mandelis (Elsevier, New York, 1987).

[2] Sánchez-Lavega A. and Salazar A. , J. Appl. Phys., 7 4, 536 and 548 (1993).

[3] Teng X.M. and Inglehart L.J., in "Photoacoustic and Photothermal Phenomena II", edited by J.C. Murphy et al., Springer Series in Optical Sciences, 62, 37 (1990). 